\title{
Treatment of COPD with Long-Acting Bronchodilators: Association Between Early and Longer-Term Clinically Important Improvement
}

\author{
Claus F Vogelmeier' \\ Ian P Naya ${ }^{2,3}$ \\ François Maltais iD ${ }^{4}$ \\ Leif Bjermer iD ${ }^{5}$ \\ Edward M Kerwin (iD) 6 \\ Lee Tombs ${ }^{7}$ \\ Paul W Jones iD ${ }^{2}$ \\ Chris Compton ${ }^{2}$ \\ David A Lipson (D) 8,9 \\ Isabelle H Boucot (iD) 2,10 \\ 'Department of Medicine, Pulmonary and \\ Critical Care Medicine, University \\ Medical Center Giessen and Marburg, \\ Philipps-Universität Marburg, Member of \\ the German Center for Lung Research \\ (DZL), Marburg, Germany; ${ }^{2}$ Global \\ Specialty \& Primary Care, GSK, \\ Brentford, Middlesex, UK; ${ }^{3}$ RAMAX Ltd, \\ Bramhall, Cheshire, UK; ${ }^{4}$ Centre De \\ Pneumologie, Institut Universitaire De \\ Cardiologie Et De Pneumologie De \\ Québec, Université Laval, Québec, \\ Canada; ${ }^{5}$ Respiratory Medicine and \\ Allergology, Lund University, Lund, \\ Sweden; ${ }^{6}$ Altitude Clinical Consulting and \\ Clinical Research Institute of Southern \\ Oregon, Medford, OR, USA; ${ }^{7}$ Precise \\ Approach Ltd, Contingent Worker on \\ Assignment at GSK, Brentford, \\ Middlesex, UK; ${ }^{8}$ Respiratory Clinical \\ Sciences, GSK, Collegeville, PA, USA; \\ ${ }^{9}$ Perelman School of Medicine, University \\ of Pennsylvania, Philadelphia, PA, USA; \\ ${ }^{10}$ Medical Emerging Markets, GSK, \\ Brentford, Middlesex, UK
}

Correspondence: Claus F Vogelmeier University Medical Center Giessen and Marburg, Philipps-Universität Marburg, Member of the German Center for Lung Research (DZL), Baldingerstraße, Marburg, 35043, Germany

Tel +49 642I/58-6645 I

Email claus.vogelmeier@med.unimarburg.de
Introduction: This post hoc analysis of the "Early MAXimization of bronchodilation for improving COPD stability" (EMAX) trial investigated whether patients achieving early clinically important improvement (CII) sustained longer-term improvements and lower risk of clinically important deterioration (CID).

Methods: Patients were randomized to umeclidinium/vilanterol, umeclidinium, or salmeterol for 24 weeks. The patient-reported outcomes (PROs) Transition Dyspnea Index (TDI), Evaluating Respiratory Symptoms, St George's Respiratory Questionnaire (SGRQ) and COPD Assessment Test (CAT) were assessed. CII, defined as attaining minimum clinically important differences (MCID) in $\geq 2$ PROs, was assessed at Weeks 4, 12 and 24. CID was defined as a deterioration in CAT, SGRQ, TDI by the MCID and/or a moderate/severe exacerbation from Day 30.

Results: Of 2425 patients, 50\%, 53\% and 51\% achieved a CII at Weeks 4, 12 and 24, respectively. Patients with a CII at Week 4 versus those without had significantly greater odds of achieving a CII at Weeks 12 and 24 (odds ratio: 5.57 [95\% CI: 4.66, 6.66]; 4.09 [95\% CI: 3.44, 4.86]). The risk of a CID was higher in patients who did not achieve a CII at Week 4 compared with patients who did (hazard ratio [95\% CI]: 2.09 [1.86, 2.34]). Patients treated with umeclidinium/vilanterol versus either monotherapy had significantly greater odds of achieving CII at Weeks 4, 12 and 24.

Conclusion: Achieving a CII at Week 4 was associated with longer-term improvement in PROs and a reduced risk of deterioration. Further research is required to investigate the importance of an early response to treatment on the long-term disease course.

Keywords: bronchodilator, clinically important improvement, clinically important deterioration, COPD symptoms, early improvement, patient-reported outcomes

\section{Plain Language Summary Why Was The Study Done?}

For patients with chronic obstructive pulmonary disease (COPD) it is important to monitor changes in their disease in response to treatment. Patient-reported outcomes (PROs) are assessments completed by patients to measure changes in their symptoms or well-being.

We aimed to understand whether improvements in COPD after 4 weeks of treatment indicate whether patients will have longer-term benefits from that treatment.

\section{What Did Researchers Do/Find?}

The "Early MAXimization of bronchodilation for improving COPD stability" (EMAX) trial compared treatment with umeclidinium/vilanterol, umeclidinium and salmeterol in patients with COPD over 24 weeks. 
Patients completed four PROs, which were analyzed to see if changes in their symptoms and well-being had a noticeable impact on their daily life. Patients who reached a threshold of improvement in at least two PROs were considered to have achieved a clinically important improvement (CII).

At Week 4, 1211 (50\%) patients had a CII and 1211 patients did not. Patients who had a CII at Week 4 were over 4 times more likely to have a CII at Week 24 than patients without a CII at Week 4. They were also less likely to have a deterioration in their COPD over the remaining duration of the trial.

More patients treated with umeclidinium/vilanterol had a CII compared with patients treated with umeclidinium or salmeterol.

\section{What Do These Results Mean?}

Early assessment of CII may indicate which patients are more likely to have longer-term benefit from a treatment. This may help enable quicker optimization of a patient's treatment.

\section{Introduction}

Chronic obstructive pulmonary disease (COPD) is usually a progressive condition with declining lung function often occurring in the early stages of the disease. ${ }^{1-3}$ Therefore, it is important to optimize maintenance treatment early in the disease course. ${ }^{4}$ It has been established that bronchodilators improve lung function and symptomatic outcomes, ${ }^{5}$ and reduce the risk of a clinically important deterioration (CID). ${ }^{6-11}$ However, it is not known whether patients with an early clinically relevant improvement in disease outcomes in response to treatment also experience longer-term clinical improvements and have a lower risk of disease worsening. This information may aid earlier treatment decisions and support timely adjustments in medication.

The impact of COPD on patients is wide-ranging and multiple patient-reported outcomes (PROs) have been developed to assess different aspects of the disease, including breathlessness, symptoms and health status. Therefore, assessment of multiple PROs may be required to identify patients who have a response to treatment. Consequently, the use of a composite endpoint called "clinically important improvement" (CII) has been proposed to assess positive treatment responses. In a post hoc analysis of the FLAME study in symptomatic patients at risk of an exacerbation, a CII composite endpoint was defined as the achievement of $\mathrm{a} \geq 100 \mathrm{~mL}$ increase in trough forced expiratory volume in 1 second $\left(\mathrm{FEV}_{1}\right)$ and a minimally $\mathrm{CII}$ on the COPD Assessment Test (CAT) or St George's Respiratory Questionnaire (SGRQ) at 4 or 12 weeks after treatment initiation. $^{12}$ Although only $18-20 \%$ of patients achieved this CII endpoint, the achievement of this CII at 4 weeks was associated with a minor signal for a reduced risk of future exacerbations. Given the low CII response rates in the FLAME study, ${ }^{12}$ a population with less severe disease, not enriched for an exacerbation history and not already using combination therapy may be more suitable for generating evidence in support of the CII concept.

The "Early MAXimization of bronchodilation for improving COPD stability" (EMAX) trial enrolled symptomatic patients with COPD who were not receiving inhaled corticosteroid (ICS) either at baseline or concurrently during the study treatment period and were at low risk of exacerbations. ${ }^{13}$ The study demonstrated that over 24 weeks, umeclidinium/vilanterol (UMEC/VI) consistently provided greater lung function and symptom improvements versus UMEC and salmeterol (SAL) monotherapy, with significant treatment differences identified as early as 4 weeks after treatment initiation. ${ }^{13}$

We hypothesized that patients with COPD who achieve a minimum clinically important difference (MCID) in two or more PROs 4 weeks after treatment initiation are more likely to continue to show positive PRO treatment responses over 24 weeks than those with MCIDs in fewer than two PROs. To assess this, we conducted a post hoc analysis of the EMAX trial and describe a novel CII composite endpoint that requires MCIDs in at least two PRO measures. Additionally, it was investigated if patients who achieved an early CII also had an improvement in perceived disease severity and a reduced risk of disease worsening.

\section{Materials and Methods}

\section{Study Design, Patients and Outcomes}

EMAX (NCT03034915; GSK study 201749) was a multicenter, double-blind, double-dummy, 3-arm parallel-group study conducted between June 2017 and June 2018. Patients were randomized 1:1:1 to UMEC/VI $62.5 / 25 \mu \mathrm{g}$ once daily via the ELLIPTA inhaler and twicedaily placebo via the DISKUS inhaler, once-daily UMEC $(62.5 \mu \mathrm{g})$ via ELLIPTA and twice-daily placebo via DISKUS, or twice-daily SAL $(50 \mu \mathrm{g})$ via DISKUS and once-daily placebo via ELLIPTA for 24 weeks. ${ }^{13}$ The study design and methods have been published previously. ${ }^{13}$ Briefly, patients were outpatients at study entry, $\geq 40$ years of age with a diagnosis of COPD, had a $\mathrm{FEV}_{1}$ /forced vital capacity $(\mathrm{FVC})$ ratio $<0.7$, a postsalbutamol $\mathrm{FEV}_{1}$ of $\geq 30-\leq 80 \%$ predicted, a CAT score $\geq 10$, and $\leq 1$ moderate exacerbation (requiring oral or 
systemic corticosteroids and/or antibiotics) and no severe exacerbations (requiring hospitalization) in the previous year. Prior to the 4-week run-in period, patients were required to be ICS-free for $\geq 6$ weeks and long-acting muscarinic antagonist/long-acting $\beta_{2}$-agonist (LAMA/ LABA)-free for $\geq 2$ weeks. Salbutamol was permitted throughout the study as needed. This study was performed according to the Declaration of Helsinki and received appropriate ethical approval (Supplementary File 1). All patients provided written informed consent at either the pre-Screening or Screening visit.

In this post hoc analysis, change from baseline in trough $\mathrm{FEV}_{1}$ and the proportion of responders for trough $\mathrm{FEV}_{1}$, self-administered computerized-Transition Dyspnea Index (SAC-TDI), SGRQ and CAT were assessed at Weeks 4, 12 and 24; Evaluating Respiratory Symptoms: COPD (E-RS) was assessed at Weeks 1-4, 9-12 and 21-24. MCID responses were defined as achieving $\geq 100 \mathrm{~mL}$ increase from baseline in trough $\mathrm{FEV}_{1},{ }^{14} \geq 1$-unit improvement from baseline (Baseline Dyspnea Index; BDI) in SAC-TDI score, ${ }^{15} \geq 2$-point reduction from baseline in E-RS total score, ${ }^{16} \geq 4$-point reduction from baseline in SGRQ score, ${ }^{17}$ and $\geq 2$-unit reduction from baseline in CAT score. ${ }^{18} \mathrm{~A}$ CII response was defined as a MCID response in at least two of the SAC-TDI, E-RS, SGRQ and CAT endpoints at the same time point. Global Assessment of Disease Severity (GADS) was rated by patients at baseline ("Mild", "Moderate", "Severe", "Very Severe"), and change in severity from baseline was rated at Week 4 on a 7-point Likert scale ("Much Better", "Better", "Slightly Better", "No Change", "Slightly Worse", "Worse", "Much Worse"). The occurrence of moderate/severe exacerbations and CID, defined as a first moderate or severe exacerbation, and/or a SGRQ deterioration ( $\geq 4$ unit increase from baseline), and/or a CAT deterioration ( $\geq 2$ unit increase from baseline), and/or a SAC-TDI deterioration ( $\geq 1$ unit decrease from baseline), were assessed after Day 30 until Week 24.

\section{Statistical Analysis}

All analyses of CII were performed post hoc for the intent-totreat (ITT) population, which comprised all patients who were randomized and received $\geq 1$ dose of study treatment. Treatment groups were pooled for analyses comparing patients who did and did not achieve a CII at Week 4 . A comparison of baseline characteristics was performed for patients with versus without a CII at Week 4; means for continuous variables were compared with a $t$-test, and proportions for categorical variables were compared with a Fisher's Exact Test. The odds of a patient achieving a CII response was calculated using generalized linear mixed models with treatment as an explanatory variable and visit, baseline SGRQ score, baseline CAT score, BDI focal score, baseline E-RS score, geographical region, number of bronchodilators per day during run-in, visit by baseline SGRQ score, visit by baseline CAT score, visit by BDI focal score, visit by baseline E-RS score and visit by treatment interactions included as covariates. The odds of a patient achieving CII at Weeks 12 and 24 by the achievement or nonachievement of CII at Week 4 were calculated using generalized linear models with covariates of number of PRO responses at Week 4 ( $<2$ or $\geq 2)$, visit, treatment, number of bronchodilators per day during run-in, geographical region, visit by treatment and visit by number of PRO responses at Week 4 interactions. Ordered odds ratios (OR) of a better GADS response category were calculated using generalized linear models with covariates of the number of PRO responses, treatment, number of bronchodilators per day during run-in and geographical region. The hazard ratio (HR) for a CID was calculated using a Cox proportional hazards model with covariates of CII at Week 4, treatment, number of bronchodilators per day during run-in, geographical region, baseline CAT score, baseline SGRQ score and SACBDI focal score. The number of patients who needed to be treated (NNT) for one additional patient to achieve a CII was calculated for UMEC/VI versus either monotherapy at Week 24.

\section{Results}

\section{Patient Demographics and Baseline Characteristics}

A total of 2425 (UMEC/VI N=812; UMEC N=804; SAL $\mathrm{N}=809$ ) patients were included in the ITT population (Table 1). Half of the patients were current smokers and $16 \%$ had experienced a moderate COPD exacerbation within the previous year. BDI, baseline E-RS, CAT and SGRQ scores and the distribution of GADS response categories were similar across treatment groups.

\section{Association Between Achieving a Cll at Week 4 and Other Outcomes Baseline Characteristics}

At Week 4, 79\%, 50\%, 26\% and $8 \%$ of patients were responders to at least 1, 2, 3 or 4 PROs, respectively. Patients achieved a CII (at least 2 PRO responses) at Week 4 with several different combinations of PRO responses, with 
Table I Patient Demographics and Baseline Characteristics

\begin{tabular}{|c|c|c|c|c|}
\hline Characteristic & UMEC/VI ( $\mathbf{N = 8} \mid \mathbf{2})$ & UMEC $(\mathrm{N}=\mathbf{8 0 4})$ & SAL $(\mathbf{N}=\mathbf{8 0 9})$ & Total $(\mathbf{N}=\mathbf{2 4 2 5})$ \\
\hline Age, years, mean (SD) & $64.6(8.4)$ & $64.9(8.5)$ & $64.4(8.5)$ & $64.6(8.5)$ \\
\hline Female, n (\%) & $319(39)$ & $327(4 I)$ & $342(42)$ & $988(4 I)$ \\
\hline Current smoker at screening, $\mathrm{n}(\%)$ & $394(49)$ & $396(49)$ & $413(5 I)$ & $1203(50)$ \\
\hline Moderate COPD exacerbation in prior year ${ }^{\mathrm{a}}, \mathrm{n}(\%)$ & $123(15)$ & $124(15)$ & $146(18)$ & $393(16)$ \\
\hline Duration of COPD, years, mean (SD) & $8.8(6.9)$ & $7.8(6.0)$ & $8.3(6.7)$ & $8.3(6.6)$ \\
\hline Use of a bronchodilator during run in, $\mathrm{n}(\%)$ & $531(65)$ & $521(65)$ & $524(65)$ & $1576(65)$ \\
\hline \multicolumn{5}{|l|}{ GOLD spirometric grade ${ }^{b}, \mathrm{n}$ (\%) } \\
\hline 2 & $518(64)$ & $529(66)$ & $522(65)$ & $1569(65)$ \\
\hline 3 & $294(36)$ & $271(34)$ & $286(35)$ & $851(35)$ \\
\hline Post salbutamol \% predicted $\mathrm{FEV}_{1}$, mean (SD) & $54.9(12.8)$ & $55.9(12.6)$ & $55.6(12.8)$ & $55.4(12.7)$ \\
\hline$\%$ reversibility to salbutamol, mean (SD) & $10.4(12.8)$ & $10.2(13.3)$ & $10.7(13.3)$ & $10.5(13.1)$ \\
\hline \multicolumn{5}{|l|}{ GADS, n (\%) } \\
\hline Mild & $136(17)$ & $139(17)$ & $136(17)$ & $4 I I(17)$ \\
\hline Moderate & $558(69)$ & $549(68)$ & $565(70)$ & $1672(69)$ \\
\hline Severe & $112(14)$ & $108(13)$ & $100(12)$ & $320(13)$ \\
\hline Very severe & $5(<1)$ & $6(<1)$ & $8(<1)$ & $19(<1)$ \\
\hline BDI score, mean (SD) & $7.0(1.8)$ & $7.0(1.9)$ & $7.1(1.8)$ & $7.0(1.9)$ \\
\hline E-RS total score, mean (SD) & $10.7(5.6)$ & $10.7(5.8)$ & $10.4(5.7)$ & $10.6(5.7)$ \\
\hline SGRQ score, mean (SD) & $44.5(16.1)$ & $45.0(16.1)$ & $44.6(16.3)$ & $44.7(16.2)$ \\
\hline CAT score, mean (SD) & 19.| (5.9) & $19.3(6.2)$ & $19.3(6.3)$ & $19.2(6.1)$ \\
\hline
\end{tabular}

Notes: ${ }^{a}$ Number of exacerbations requiring oral or systemic corticosteroids and/or antibiotics (moderate) in 12 months prior to screening (patients with $>I$ moderate exacerbation or with a severe exacerbation [requiring hospitalization] were excluded); ${ }^{\text {an }}$ additional 4 (<I\%) patients with GOLD grade I were randomized (UMEC $n=3$; SAL $n=1)$.

Abbreviations: BDI, Baseline Dyspnea Index; CAT, COPD Assessment Test; COPD, chronic obstructive pulmonary disease; E-RS, Evaluating Respiratory Symptoms: COPD; FEV , forced expiratory volume in I second; GADS, Global Assessment of Disease Severity; GOLD, Global Initiative for Chronic Obstructive Lung Disease; SAL, salmeterol; SD, standard deviation; SGRQ, St George's Respiratory Questionnaire; UMEC, umeclidinium; VI, vilanterol.

a greater proportion of patients achieving a CAT or SAC-TDI response and a smaller proportion achieving an E-RS or SGRQ response (Supplementary Figure 1).

Patients who achieved a CII at Week 4 had significantly greater percent reversibility to salbutamol, mean baseline rescue medication use, E-RS score, CAT score and SGRQ total score and a significantly smaller proportion of patients were receiving a long-acting bronchodilator at baseline compared with those without a CII at Week 4 (Table 2). More patients with a CII at Week 4 rated their COPD as moderate or severe at baseline, compared with patients without a CII.

\section{Achieving a Cll at Weeks 12 and 24}

Overall, $50 \%, 53 \%$ and $51 \%$ of patients in the ITT population achieved a CII at Weeks 4, 12 and 24, respectively. Patients achieving a CII at Week 4 were more than 5-fold more likely to be responders at Week 12 and 4-fold more likely to be responders at Week 24 compared with patients who did not achieve a CII at Week 4 (both $\mathrm{p}<0.001)$ (Figure 1).

\section{Patients' Global Assessment of Disease Severity}

The proportion of patients reporting a GADS of "Slightly Better", "Better" or "Much Better" at Week 4 was greater for patients who achieved a CII at Week $4(\mathrm{n}=955 / 1210 ; 79 \%)$ compared with those who did not ( $\mathrm{n}=417 / 1100 ; 38 \%)$, and increased in parallel with the number of PRO responses (Table 3). Furthermore, patients who achieved a CII at Week 4 had a significantly higher ordered OR of an improvement in GADS at Week 4 versus those who did not achieve a CII at Week $4(\mathrm{p}<0.001)$. Patients with $1,2,3$ or 4 PRO responses at Weeks 4 also had significantly higher ordered ORs of an improvement in GADS at Week 4 versus those 
Table 2 Association Between Patient Demographics and Baseline Characteristics and the Achievement of a Cll at Week 4

\begin{tabular}{|c|c|c|c|}
\hline Characteristic & No Cll at Week $4(\mathrm{~N}=|2| I)$ & CII at Week $4(N=12 \mid 1)$ & $P$ value \\
\hline Age, years, mean (SD) & $64.6(8.4)$ & $64.6(8.5)$ & 0.956 \\
\hline Female, n (\%) & $481(40)$ & $506(42)$ & 0.321 \\
\hline Current smoker at screening, $\mathrm{n}(\%)$ & $597(49)$ & $604(50)$ & 0.807 \\
\hline Duration of COPD, years, mean (SD) & $8.2(6.4)$ & $8.4(6.7)$ & 0.408 \\
\hline $\begin{array}{l}\text { Baseline rescue medication use, puffs/day, mean } \\
\text { (SD) }\end{array}$ & $2.0(2.3)$ & $2.3(2.6)$ & 0.003 \\
\hline No maintenance medication during run-in, $\mathrm{n}(\%)$ & $328(27)$ & $421(35)$ & $<0.001$ \\
\hline Trough FEV, mL, mean (SD) & $1505(5 \mid 6)$ & $1476(5 \mid 8)$ & 0.164 \\
\hline $\begin{array}{l}\text { Post-bronchodilator \% predicted } \mathrm{FEV}_{1} \text {, mean } \\
\text { (SD) }\end{array}$ & $55.5(13.0)$ & $55.4(12.5)$ & 0.835 \\
\hline \% reversibility to salbutamol, mean (SD) & $9.9(12.7)$ & $11.0(13.5)$ & 0.037 \\
\hline \multicolumn{4}{|l|}{ GADS, n (\%) } \\
\hline Mild & $235(19)$ & $175(14)$ & $0.002^{\mathrm{a}}$ \\
\hline Moderate & $818(68)$ & $854(7 I)$ & \\
\hline Severe & $147(12)$ & $173(14)$ & \\
\hline Very severe & $9(<1)$ & $9(<1)$ & \\
\hline GOLD spirometric grade, n (\%) & - & - & \\
\hline $\mathrm{I}$ and $2^{\mathrm{b}}$ & $786(65)$ & $785(65)$ & 0.966 \\
\hline 3 & $424(35)$ & $426(35)$ & \\
\hline SAC-BDI focal score, mean (SD) & $7.1(1.9)$ & $7.0(1.8)$ & 0.109 \\
\hline E-RS total score, mean (SD) & $10.3(5.8)$ & $10.9(5.7)$ & 0.008 \\
\hline CAT score, mean (SD) & I8.2 (5.8) & $20.2(6.3)$ & $<0.001$ \\
\hline SGRQ total score, mean (SD) & $42.8(15.9)$ & $46.6(16.2)$ & $<0.001$ \\
\hline
\end{tabular}

Notes: ${ }^{\text {P}}$ Proportions compared using a Wilcoxon rank sum test; ${ }^{b}$ two patients in each subgroup were categorized as GOLD grade I COPD.

Abbreviations: CAT, COPD Assessment Test; Cll, clinically important improvement; COPD, chronic obstructive pulmonary disease; E-RS, Evaluating Respiratory Symptoms:COPD; FEV , forced expiratory volume in I second; GADS, Global Assessment of Disease Severity; GOLD, Global Initiative for Chronic Obstructive Lung Disease; SD, standard deviation; SAC-BDI, self-assessment computerized-Baseline Dyspnea Index; SGRQ, St George's Respiratory Questionnaire.

with zero PRO responses at Week 4 (all $\mathrm{p}<0.001)$ and the magnitude of the ordered ORs was greater for patients with a higher number of PRO responses (Table 4).

\section{Clinically Important Deterioration}

Among patients achieving a CII at Week 4, 45\% experienced a CID after Day 30; in contrast, 67\% of patients who did not achieve a CII at Week 4 experienced a CID after Day 30 (Figure 2A). Similarly, the proportion of patients experiencing a CID after Day 30 decreased with the increasing number of positive PRO responses at Week 4 (Figure 2B). The risk of a CID was twice as high in patients who did not achieve a CII at Week 4 compared with patients who did achieve a CII at Week 4 (Figure 2C).
The proportion of patients experiencing a moderate or severe exacerbation after Day 30 was numerically lower in patients who achieved a CII at Week 4 compared with those who did not achieve a CII at Week 4 (11\% vs $14 \%)$; however, exacerbations were infrequent in this study population (Supplementary Figure 2).

\section{Comparison of Cll by Treatment}

At Week 4, a smaller proportion of patients receiving UMEC/VI had 0 or 1 PRO responses (18\% and $27 \%$, respectively) compared with either UMEC (24\% and $29 \%$ ) or SAL (22\% and $30 \%)$; a greater proportion of patients receiving UMEC/VI achieved 4 PRO responses (11\%) compared with UMEC (8\%) and SAL (6\%). 


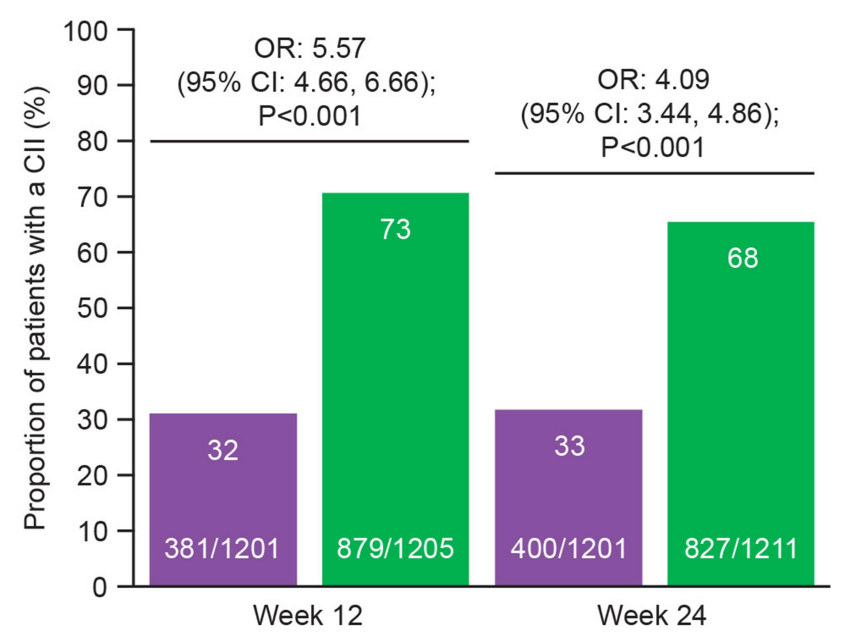

Did not achieve a Cll at Week 4

Achieved a Cll at Week 4

Figure I Proportion of patients achieving a Cll at Weeks 12 and 24 stratified by the achievement of a Cll at Week 4.

Abbreviations: $\mathrm{Cl}$, confidence interval; Cll, clinically important improvement; OR, odds ratio.

A greater proportion of patients achieved a CII with UMEC/VI (56-58\%) compared with UMEC (47-52\%) and SAL (48-49\%) at Weeks 4, 12 and 24 (Figure 3). The odds of a patient achieving a CII were also significantly greater with UMEC/VI versus UMEC and SAL at Weeks 4, 12 and 24, and the magnitude of the ORs were consistent between Weeks 4 and 24 (Figure 3). At Week 24 the NNT (95\% CI) for CII was $11(8,23)$ for UMEC/VI versus UMEC and 11 $(8,24)$ for UMEC/VI versus SAL. In patients who achieved a CII with UMEC/VI at Week 4, 72\% also achieved a CII at Week 24 (Table 5). Similar results were seen with UMEC and SAL with $67 \%$ and $66 \%$, respectively, achieving a CII at both Weeks 4 and 24. Furthermore, with all treatments most patients who did not have a CII at Week 4 also did not have CII at Week 24 (Table 5).

\section{Discussion}

In this post hoc analysis of the EMAX trial, a novel composite endpoint of CII requiring concordant MCID responses in at least two PRO measures was used to assess whether early responses to maintenance bronchodilator treatments are associated with longer-term treatment responses in symptomatic patients with COPD. When compared with patients without a CII at Week 4, patients with a CII at Week 4 had 5- and 4-fold greater odds of achieving a CII at Weeks 12 and 24, respectively,

Table 3 Ordered OR of GADS Improvement on the 7-Point Likert Scale at Week 4

\begin{tabular}{|c|c|c|c|c|c|c|c|}
\hline \multirow{2}{*}{$\begin{array}{l}\text { GADS Response at Week } \\
4, \mathrm{n}(\%)\end{array}$} & \multirow[b]{2}{*}{$\begin{array}{l}\text { No CII at } \\
\text { Week } 4 \\
(n=\mid 100)\end{array}$} & \multirow[b]{2}{*}{$\begin{array}{l}\text { Cll at Week } \\
4(\mathrm{~N}=|2| 0)\end{array}$} & \multicolumn{5}{|c|}{ Number of PRO Responses ${ }^{a}$ at Week 4} \\
\hline & & & $\begin{array}{c}0 \\
(n=407)\end{array}$ & I $(n=693)$ & $2(n=579)$ & $3(n=433)$ & $4(n=198)$ \\
\hline Much Better & $17(2)$ & $85(7)$ & $2(<1)$ & $15(2)$ & $17(3)$ & $31(7)$ & $37(19)$ \\
\hline Better & $68(6)$ & $308(25)$ & $9(2)$ & 59 (9) & 107 (18) & $|2|(28)$ & $80(40)$ \\
\hline Slightly Better & $332(30)$ & $562(46)$ & $83(20)$ & $249(36)$ & $264(46)$ & $225(52)$ & $73(37)$ \\
\hline No Change & $509(46)$ & $215(18)$ & $213(52)$ & $296(43)$ & $158(27)$ & $50(12)$ & $7(4)$ \\
\hline Slightly Worse & $140(13)$ & $37(3)$ & $74(18)$ & $66(10)$ & $31(5)$ & $5(1)$ & $I(<1)$ \\
\hline Worse & $28(3)$ & $3(<1)$ & $21(5)$ & $7(1)$ & $2(<1)$ & $\mathrm{I}(<\mathrm{I})$ & 0 \\
\hline Much Worse & $6(<1)$ & 0 & $5(1)$ & I $(<1)$ & 0 & 0 & 0 \\
\hline $\begin{array}{l}\text { OR of better response }{ }^{b} \text { vs } \\
\text { no } \mathrm{CII}(95 \% \mathrm{Cl})\end{array}$ & - & $\begin{array}{c}5.56(4.69 \\
6.58) ; p<0.001\end{array}$ & - & - & - & - & - \\
\hline $\begin{array}{l}\text { OR of better response }{ }^{b} \text { vs } 0 \\
\text { PRO responses }(95 \% \mathrm{Cl})\end{array}$ & - & - & - & $\begin{array}{c}2.91(2.30 \\
3.69) ; \\
p<0.001\end{array}$ & $\begin{array}{c}6.67(5.18 \\
8.61) \\
p<0.001\end{array}$ & $\begin{array}{c}\text { I5.96 (I2.07, } \\
21.10) \\
p<0.001\end{array}$ & $\begin{array}{c}42.07 \text { (29.58, } \\
59.83) ; \\
p<0.001\end{array}$ \\
\hline
\end{tabular}

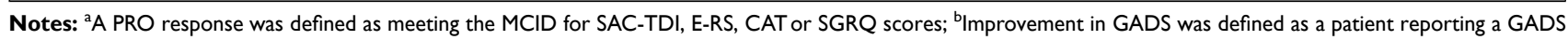
response of Slightly Better, Better or Much Better at Week 4.

Abbreviations: CAT, COPD Assessment Test; Cl, confidence interval; Cll, clinically important improvement; COPD, chronic obstructive pulmonary disease; E-RS, Evaluating Respiratory Symptoms:COPD; GADS, Global Assessment of Disease Severity; MCID, minimal clinically important difference; OR, odds ratio; PRO, patientreported outcome; SAC-TDI, self-administered computerized-Transition Dyspnea Index; SGRQ, St George's Respiratory Questionnaire. 
Table 4 Combinations of PRO Responses at Week 4 by Treatment

\begin{tabular}{|c|c|c|c|}
\hline $\begin{array}{l}\text { Positive PRO Responses, } \\
\text { n (\%) }\end{array}$ & $\begin{array}{l}\text { UMEC/VI } \\
(\mathrm{N}=8 \mid 2)\end{array}$ & $\begin{array}{l}\text { UMEC } \\
(N=804)\end{array}$ & $\begin{array}{c}\text { SAL } \\
(N=809)\end{array}$ \\
\hline O PROs & I46 (I8) & $194(24)$ & $174(22)$ \\
\hline I PRO & $219(27)$ & 235 (29) & $246(30)$ \\
\hline CAT score & $81(10)$ & $102(13)$ & $119(15)$ \\
\hline SAC-TDI & $65(8)$ & $64(8)$ & $67(8)$ \\
\hline SGRQ total score & $45(6)$ & $47(6)$ & $39(5)$ \\
\hline E-RS total score & $28(3)$ & $22(3)$ & $21(3)$ \\
\hline 2 PROs & $210(26)$ & $172(2 \mid)$ & $198(24)$ \\
\hline SGRQ + CAT & $57(7)$ & $50(6)$ & $64(8)$ \\
\hline SAC-TDI + CAT & $66(8)$ & $46(6)$ & $52(6)$ \\
\hline SGRQ + SAC-TDI & $34(4)$ & $28(3)$ & $36(4)$ \\
\hline SAC-TDI + E-RS & $26(3)$ & $20(2)$ & $18(2)$ \\
\hline CAT+ E-RS & $18(2)$ & $20(2)$ & $23(3)$ \\
\hline SGRQ + E-RS & $9(1)$ & $8(<1)$ & $5(<1)$ \\
\hline 3 PROs & $150(18)$ & 140 (I7) & $143(18)$ \\
\hline SGRQ + SAC-TDI + CAT & $82(10)$ & $71(9)$ & $70(9)$ \\
\hline SAC-TDI + CAT + E-RS & $28(3)$ & $35(4)$ & $25(3)$ \\
\hline SGRQ + CAT + E-RS & $18(2)$ & $19(2)$ & $31(4)$ \\
\hline SGRQ + SAC-TDI + E-RS & $22(3)$ & $15(2)$ & $17(2)$ \\
\hline $\begin{array}{l}4 \text { PROs } \\
\text { SGRQ + SAC-TDI + } \\
\text { CAT + E-RS }\end{array}$ & $87(11)$ & $63(8)$ & $48(6)$ \\
\hline $\begin{array}{l}\text { No Cll achieved ( } 0 \text { or I } \\
\text { PRO) }\end{array}$ & $365(45)$ & $429(53)$ & $420(52)$ \\
\hline $\begin{array}{l}\text { CII achieved (2, } 3 \text { or } 4 \\
\text { PROs) }\end{array}$ & $447(55)$ & $375(47)$ & $389(48)$ \\
\hline
\end{tabular}

Abbreviations: CAT, COPD Assessment Test; Cll, clinically important improvement; COPD, chronic obstructive pulmonary disease; E-RS, Evaluating Respiratory Symptoms:COPD; PRO, patient-reported outcome; SAC TDI, self-administered computerized-Transition Dyspnea Index; SAL, salmeterol; SGRQ, St George's Respiratory Questionnaire; UMEC, umeclidinium; VI, vilanterol.

suggesting that patients with early treatment responses had greater odds of maintaining their response over a longer period of time. Additionally, a lower proportion of patients with a CII at Week 4 had a CID after Day 30 compared with patients without a CII at Week 4 . These data suggest that a positive treatment response in CII as early as Week 4 is associated with greater odds of symptom improvements and a reduced likelihood of deterioration at 24 weeks. As such, early assessment of treatment response may be a useful guide to the likely longer-term benefits of a treatment and may facilitate early treatment decisions and aid early treatment optimization.

Achieving the composite endpoint of CII at Week 4 was not associated with fewer subsequent moderate/ severe exacerbations, possibly because there were few exacerbations during the study as the population had a low exacerbation risk. The relatively short study duration may also have contributed to this. Using an alternative definition of CII which included improvement in lung function, Kostikas et al demonstrated that in patients with a history of exacerbations there was only a weak association between $\mathrm{CII}$ and future exacerbation risk. ${ }^{12}$ Other studies have also shown conflicting evidence regarding the association of symptoms with the future risk of an exacerbation; for example, worse breathlessness according to the modified Medical Research Council score has been shown to be associated with an increased risk of an exacerbation whereas 24-hour COPD symptoms have been found not to be associated with exacerbation risk. ${ }^{19,20}$

The Global Initiative for Chronic Obstructive Lung Disease strategy report suggests that regular monitoring of changes in symptoms and health status is important to measure treatment response, ${ }^{5}$ therefore, four PROs were selected to form the CII endpoint in this study to enable a comprehensive assessment of patient benefit. To further investigate the potential use of the CII it will be important to assess the contribution each PRO makes to the prognostic ability of the endpoint. The present data suggest that the responder status of the CAT, SAC-TDI, SGRQ and E-RS are not interchangeable, as patients often achieved a MCID in only one or two of them. In fact, these PROs likely reflect different dimensions of COPD, as suggested by the low correlation between some of the measures. Although the correlation between CAT and SGRQ scores is typically quite high (convergent validity using Pearson's correlation coefficient: $0.69-0.82),{ }^{21}$ a one unit difference in score (equivalent to $1 \%$ change in SGRQ total score and $<3 \%$ change in CAT total score) can result in a different responder status for a patient. There was a higher concordance between responder rates with certain combinations of PROs compared with others; for example, $27 \%$ of the patients achieved a CII that included responses to both SGRQ and CAT, whereas $14 \%$ achieved a CII that included responses to both SGRQ and E-RS. Accordingly, a post hoc analysis of the 12-week CRYSTAL study, which, similar to this study had a population of patients at low exacerbation risk, reported a similarly weak association between responders to different PRO measures. ${ }^{22}$ Indeed, the CRYSTAL study found that $64 \%$ of the patients were responders to at least one PRO and $33 \%$ were responders to at least two PROs, ${ }^{22}$ 
A

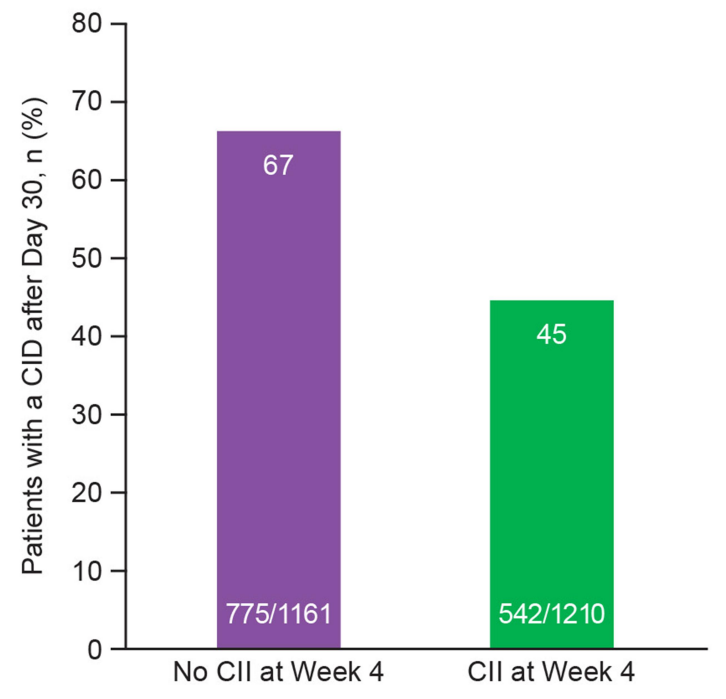

B

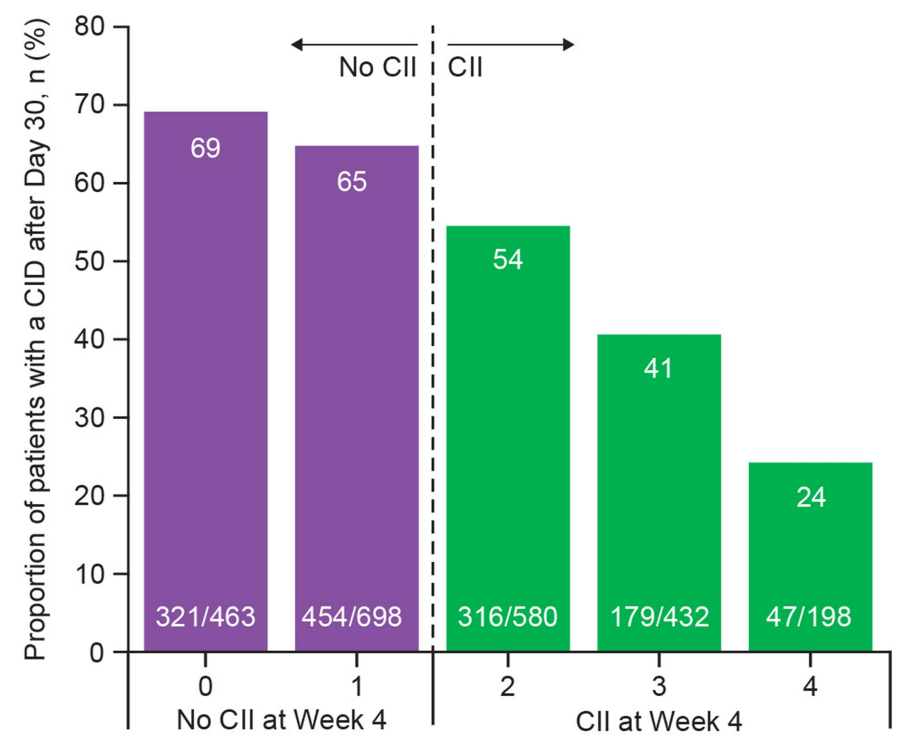

Number of PRO responses at Week 4

\section{C}

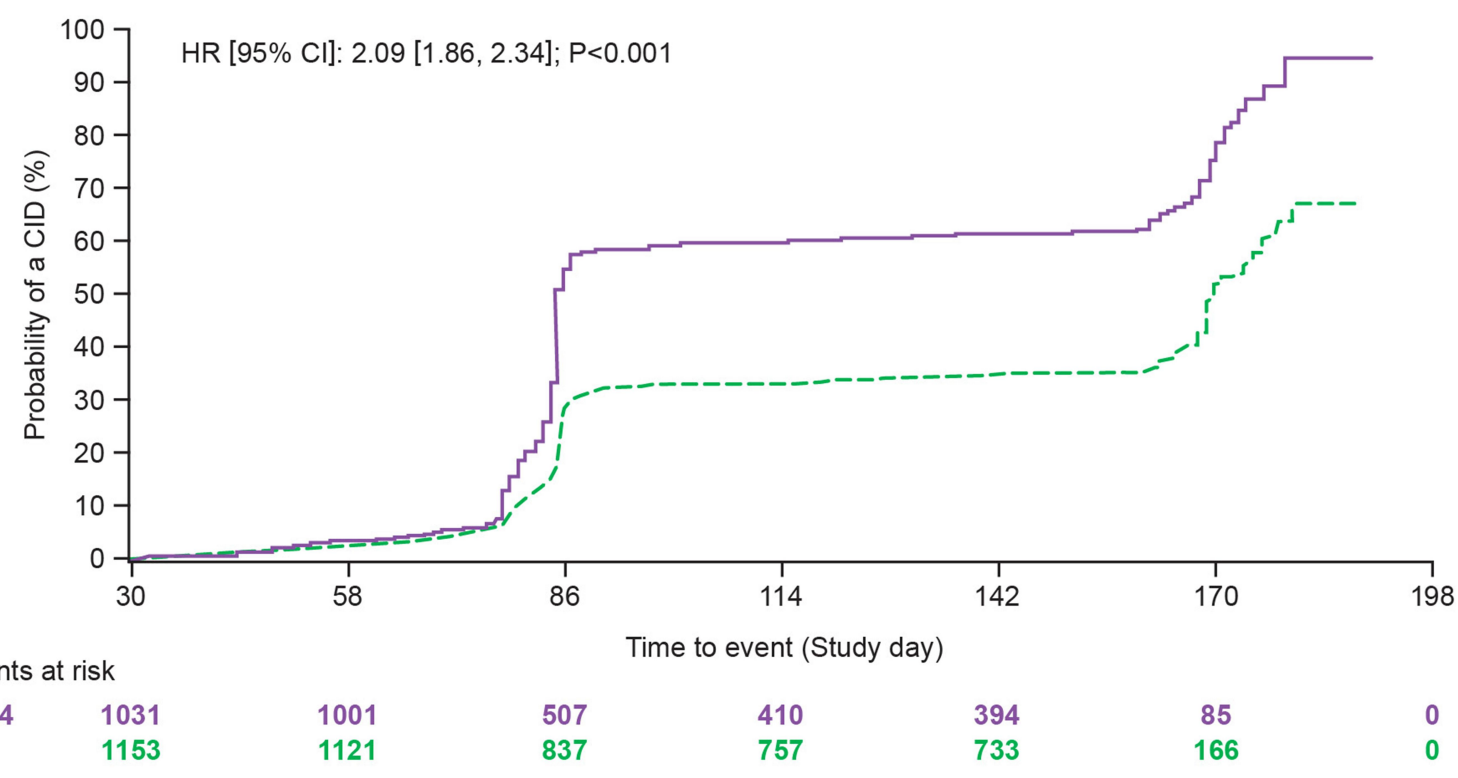

Number of patients at risk

$\begin{array}{lllllll}\text { No CII at Week 4 } & 1031 & 1001 & 507 & 410 & 394 & 85 \\ \text { CII at Week 4 } & 1153 & 1121 & 837 & 757 & 733 & 166\end{array}$

Figure 2 Proportion of patients with a Clinically Important Deterioration (CID) ${ }^{\mathrm{a}}$ after Day 30 by: (A) achievement of a Cll at Week 4; (B) the number of PRO responses at Week 4; (C) Kaplan-Meier curve of time to first CID in patients by achievement of CII at Week 4.

Notes: ${ }^{a} \mathrm{~A}$ CID was defined as a first moderate or severe exacerbation, and/or a SGRQ deterioration ( $\geq 4$ units from baseline), and/or a CAT deterioration ( $\geq 2$ units from baseline), and/or a SAC-TDI deterioration ( $\geq$ I unit decrease from baseline).

Abbreviations: CAT, COPD Assessment Test; CID, clinically important deterioration; $\mathrm{Cl}$, confidence interval; CII, clinically important improvement; COPD, chronic obstructive pulmonary disease; HR, hazard ratio; PRO, patient-reported outcome; SAC-TDI, self-administered computerized-Transition Dyspnea Index; SGRQ, St George's Respiratory Questionnaire.

similar to the $79 \%$ and $50 \%$, respectively, achieving these outcomes at Week 4 in the current study. This supports the hypothesis that when using a responder analysis approach, the use of a composite endpoint such as the CII may be a more reliable tool for detecting a broader range of improvements in symptoms and health status than the monitoring of single individual subjective PRO.

In clinical practice, it is time-consuming and impractical to monitor several different PRO measures; however, the CII may be a useful endpoint in clinical trials as 


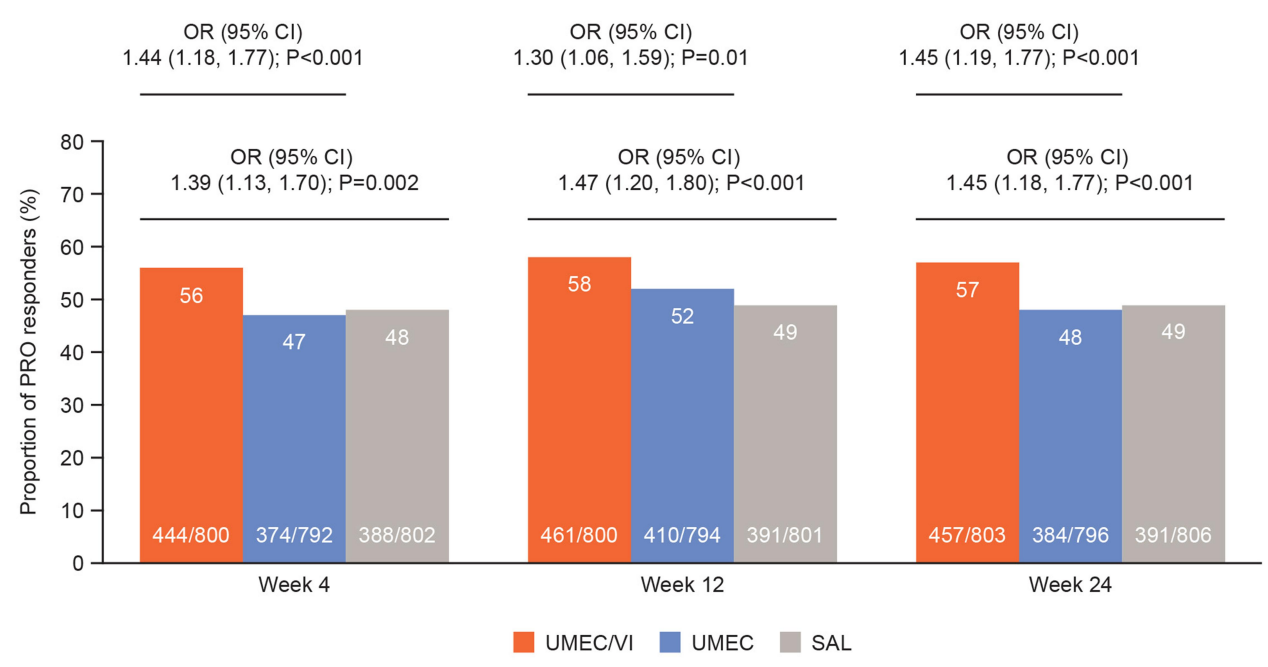

Figure 3 Proportion of patients achieving CII (reaching MCID in at least two PROs) at Weeks 4, 12 and $24^{\mathrm{a}}$.

Notes: analysis of patients with a responder status for $\geq 2$ PROs at each visit.

Abbreviations: $\mathrm{Cl}$, confidence interval; Cll, clinically important improvement; MCID, minimum clinically important difference; OR, odds radio; PRO, patient-reported outcome; SAL, salmeterol; UMEC, umeclidinium; VI, vilanterol.

achievement of a CII at an early time point may be indicative of longer-term treatment efficacy. In this analysis, consistent treatment differences in CII were observed between UMEC/VI and both monotherapies as early as Week 4, with a CII experienced by a significantly greater proportion of patients treated with UMEC/VI (56\%) versus UMEC (47\%) and SAL (48\%). These treatment differences were maintained or slightly increased throughout the 24-week study period. As all bronchodilator classes performed consistently throughout the study period, this suggests that treatment success with LAMA/LABA, LAMA and LABA can be evaluated as early as 4 weeks after treatment initiation using the CII endpoint. In addition, the greater proportion of patients achieving CII with UMEC/VI compared with monotherapy provides further evidence of treatment benefits of dual bronchodilator therapy.

There are potential limitations to consider when interpreting this analysis. It was a post hoc analysis of the EMAX trial, in which the outcomes were only measured for up to 24 weeks; prospective and longer-term analyses are required to further investigate the CII. However, as COPD is a progressive disease, necessitating treatment augmentation with time, the need for long-term studies must be balanced against the need for therapeutic pragmatism in designing trials. This was an analysis of a randomized control trial; analyses of real-world data are also required to investigate the potential relevance of these findings to clinical practice. Furthermore, compared with patients who did not have a CII at Week 4, patients who

Table 5 Proportion of Patients Who Maintained Their Week 4 Cll Status at Week 24

\begin{tabular}{|c|c|c|c|}
\hline & \multicolumn{3}{|c|}{ Patients Who Achieved CII at Week 4} \\
\hline & UMEC/VI (n=447) & UMEC $(n=375)$ & SAL $(n=389)$ \\
\hline Patients who achieved Cll at Week 24, n (\%) & $322(72)$ & $250(67)$ & $255(66)$ \\
\hline \multirow[t]{3}{*}{ Patients who did not achieve Cll at Week 24, n (\%) } & $125(28)$ & $125(33)$ & $134(34)$ \\
\hline & \multicolumn{3}{|c|}{ Patients without CII response at Week 4} \\
\hline & UMEC/VI (n=362) & UMEC $(n=423)$ & SAL $(n=4 \mid 6)$ \\
\hline Patients who achieved $\mathrm{Cll}$ at Week 24, n (\%) & $135(37)$ & $132(3 \mid)$ & $133(32)$ \\
\hline Patients who did not achieve Cll at Week 24, n (\%) & $227(63)$ & 291 (69) & $283(68)$ \\
\hline
\end{tabular}

Notes: The proportion of patients who maintained their Week 4 Cll status at Week 24 is shown in bold.

Abbreviations: CII, clinically important improvement; SAL, salmeterol; UMEC, umeclidinium; VI, vilanterol. 
achieved a CII at Week 4 had significantly worse E-RS, CAT and SGRQ scores at baseline, therefore regression to the mean effect may have affected the results. Also, factors such as change in smoking status during the study, patient comorbidities, treatment adherence and device errors have not been considered in this analysis. Finally, these data must be interpreted in the context of the EMAX patient population, which consisted of symptomatic patients with a low exacerbation risk who were not receiving ICS nor had prior use of combination maintenance therapies. However, this is an important population for the analysis of $\mathrm{CII}$ and provides new information to complement the analysis of a CII endpoint in the FLAME study, where the population had a history of exacerbations and prior use of combination therapy. ${ }^{12}$

\section{Conclusion}

The results of this post hoc analysis suggest that achieving a clinically significant improvement in two or more PROs after 4 weeks of treatment is associated with longer-term improvements in symptom severity and health status and is associated with a reduced incidence of future CID than achieving a single or no positive PRO responses. This suggests that response to treatment could be assessed soon after treatment initiation and provides further evidence of the importance of early treatment optimization. In a complex chronic and progressive disease like COPD, no consensus exists on what constitutes treatment success; these preliminary findings suggest further research may be warranted to address the importance of achieving concordant patient-centric responses.

\section{Abbreviations}

BDI, Baseline Dyspnea Index; CAT, COPD Assessment Test; CI, confidence interval; CID, clinically important deterioration; CII, clinically important improvement; COPD, chronic obstructive pulmonary disease; EMAX, Early MAXimization of bronchodilation for improving COPD stability; E-RS, Evaluating Respiratory Symptoms:COPD; $\mathrm{FEV}_{1}$, forced expiratory volume in 1 second; FVC, forced vital capacity; GADS, Global Assessment of Disease Severity; GOLD, Global Initiative for Chronic Obstructive Lung Disease; HR, hazard ratio; ICS, inhaled corticosteroid; IEC, independent ethics committee; IRB, institutional review board; ITT, intent-totreat; LABA, long-acting $\beta_{2}$-agonist; LAMA, long-acting muscarinic antagonist; MCID, minimum clinically important differences; NNT, number needed to treat; OR, odds ratio; PRO, patient-reported outcome; SAC-TDI, selfadministered computerized-Transition Dyspnea Index; SAL, salmeterol; SD, standard deviation; SGRQ, St George's Respiratory Questionnaire; TDI, Transition Dyspnea Index; UMEC, umeclidinium; VI, vilanterol.

\section{Data Sharing Statement}

Anonymized individual participant data and study documents can be requested for further research from www. clinicalstudydatarequest.com.

\section{Acknowledgments}

Editorial support (in the form of writing assistance, assembling figures, collating author comments, grammatical editing, and referencing) was provided by Katie White, $\mathrm{PhD}$, and Liam Campbell, PhD, of Fishawack Indicia Ltd, UK, part of Fishawack Health, and was funded by GSK. ELLIPTA and DISKUS are owned by/licensed to the GSK group of companies.

\section{Author Contributions}

All authors made substantial contributions to conception and design, acquisition of data, or analysis and interpretation of data; took part in drafting the article or revising it critically for important intellectual content; agreed to submit to the current journal; gave final approval of the version to be published; and agree to be accountable for all aspects of the work.

\section{Funding}

This study was funded by GlaxoSmithKline (GSK study 201749; NCT03034915).

\section{Disclosure}

CFV has received grants from AstraZeneca, Boehringer Ingelheim, Chiesi, GSK, Grifols, Mundipharma, Novartis, and the German Federal Ministry of Education and Research (BMBF) Competence Network Asthma and COPD (ASCONET), and has received personal fees from AstraZeneca, Boehringer Ingelheim, Berlin Chemie/ Menarini, Chiesi, CSL Behring, GSK, Grifols, MedUpdate, Nuvaira, Novartis and Teva. EMK has served on advisory boards, speaker panels or received travel reimbursement for Amphastar, AstraZeneca, Boehringer Ingelheim, GSK, Mylan, Novartis, Pearl, Sunovion, Teva and Theravance, and has received consulting fees from Cipla, Connect Biopharma, and GSK. IHB, DAL, CC 
and PWJ are employees of GSK and hold stock and shares in GSK. FM has received research grants for participating in multicenter trials for AstraZeneca, Boehringer Ingelheim, GSK, Sanofi and Novartis, and has received unrestricted research grants and personal fees from Boehringer Ingelheim, Grifols and Novartis. FM also reports financial participation in Oxynov, a company which is developing an oxygen delivery system. IPN was an employee of GSK at the time of the study, holds stocks and shares in GSK, and was a contingent worker on assignment at AstraZeneca. LT is a contingent worker on assignment at GSK. LB has received honoraria for giving a lecture or attending an advisory board for Airsonett, ALK-Abelló, AstraZeneca, Boehringer Ingelheim, Chiesi, GSK, Meda, Novartis and Teva. The authors report no other conflicts of interest in this work.

\section{References}

1. Tantucci C, Modina D. Lung function decline in COPD. Int J Chron Obstruct Pulmon Dis. 2012;7:95-99. doi:10.2147/COPD.S27480

2. Sun Y, Zhou J. New insights into early intervention of chronic obstructive pulmonary disease with mild airflow limitation. Int J Chron Obstruct Pulmon Dis. 2019;14:1119-1125. doi:10.2147/ COPD.S205382

3. Sutherland ER, Cherniack RM. Management of chronic obstructive pulmonary disease. $N$ Engl $J$ Med. 2004;350(26):2689-2697. doi:10.1056/NEJMra030415

4. Decramer M, Celli B, Kesten S, Lystig T, Mehra S, Tashkin DP. Effect of tiotropium on outcomes in patients with moderate chronic obstructive pulmonary disease (UPLIFT): a prespecified subgroup analysis of a randomised controlled trial. Lancet. 2009;374(9696):1171-1178. doi:10.1016/s0140-6736(09)61298-8

5. Global Initiative for Chronic Obstructive Lung Disease (GOLD). Global strategy for the diagnosis, management, and prevention of chronic obstructive pulmonary disease; 2021. Accessed January 2021.

6. Maleki-Yazdi MR, Singh D, Anzueto A, Tombs L, Fahy WA, Naya I. Assessing short-term deterioration in maintenance-naive patients with COPD receiving umeclidinium/vilanterol and tiotropium: a Pooled Analysis of Three Randomized Trials. Adv Ther. 2017;33 (12):2188-2199. doi:10.1007/s12325-016-0430-6

7. Naya IP, Tombs L, Lipson DA, Compton C. Preventing clinically important deterioration of COPD with addition of umeclidinium to inhaled corticosteroid/long-acting beta2-agonist therapy: an integrated post hoc analysis. Adv Ther. 2018;35(10):1626-1638. doi:10.1007/ s12325-018-0771-4

8. Singh D, Maleki-Yazdi MR, Tombs L, Iqbal A, Fahy WA, Naya I. Prevention of clinically important deteriorations in COPD with umeclidinium/vilanterol. Int $J$ Chron Obstruct Pulmon Dis. 2016;11:1413-1424. doi:10.2147/copd.s101612
9. Anzueto AR, Vogelmeier CF, Kostikas K, et al. The effect of indacaterol/glycopyrronium versus tiotropium or salmeterol/fluticasone on the prevention of clinically important deterioration in COPD. Int J Chron Obstruct Pulmon Dis. 2017;12:1325-1337. doi:10.2147/copd.s133307

10. D'Urzo A, Bader G, Shen S, Goyal P, Altman P. Comparison of glycopyrronium versus tiotropium on the time to clinically important deteriorations in patients with COPD: a post-hoc analysis of randomized trials. NPJ Prim Care Respir Med. 2018;28(1):18. doi:10.1038/s41533-018-0084-8

11. Singh D, D’Urzo AD, Chuecos F, Muñoz A, Garcia Gil E. Reduction in clinically important deterioration in chronic obstructive pulmonary disease with aclidinium/formoterol. Respir Res. 2017;18(1):106. doi:10.1186/s12931-017-0583-0

12. Kostikas K, Mackay AJ, Vogelmeier CF, et al. Early Clinically Important Improvement (ECII) and exacerbation outcomes in COPD patients. Int $J$ Chron Obstruct Pulmon Dis. 2020;15:1831-1838. doi:10.1183/13993003.congress-2018.OA1657

13. Maltais F, Bjermer L, Kerwin EM, et al. Efficacy of umeclidinium/ vilanterol versus umeclidinium and salmeterol monotherapies in symptomatic patients with COPD not receiving inhaled corticosteroids: the EMAX randomised trial. Respir Res. 2019;20(1):238. doi:10.1186/s12931-019-1193-9

14. Donohue JF. Minimal clinically important differences in COPD lung function. Int J Chron Obstruct Pulmon Dis. 2005;2(1):111-124. doi:10.1081/copd-200053377

15. Mahler DA, Witek TJ Jr. The MCID of the transition dyspnea index is a total score of one unit. Copd. 2005;2(1):99-103. doi:10.1081/ copd-200050666

16. Leidy NK, Murray LT, Monz BU, et al. Measuring respiratory symptoms of COPD: performance of the EXACT- Respiratory Symptoms Tool (E-RS) in three clinical trials. Respir Res. 2014;15(1):124. doi:10.1186/s12931-014-0124-z

17. Jones PW. St. George's respiratory questionnaire: MCID. COPD. 2005;2(1):75-79. doi:10.1081/copd-200050513

18. Kon SS, Canavan JL, Jones SE, et al. Minimum clinically important difference for the COPD assessment test: a prospective analysis. Lancet Respir Med. 2014;2(3):195-203. doi:10.1016/s22132600(14)70001-3

19. Miravitlles M, Worth H, Soler-Cataluña JJ, et al. The relationship between 24-hour symptoms and COPD exacerbations and healthcare resource use: results from an Observational Study (ASSESS). Int J Chron Obstruct Pulmon Dis. 2016;13(5):561-568. doi:10.3109/15412555.2016.1150447

20. Calverley PM, Tetzlaff K, Dusser D, et al. Determinants of exacerbation risk in patients with COPD in the TIOSPIR study. Int J Chron Obstruct Pulmon Dis. 2017;12:3391-3405. doi:10.2147/copd.s145814

21. Gupta N, Pinto LM, Morogan A, Bourbeau J. The COPD assessment test: a systematic review. Eur Respir J. 2014;44(4):873-884. doi:10.1183/09031936.00025214

22. Kostikas K, Greulich T, Mackay AJ, et al. Treatment response in COPD: does FEV1 say it all? A post hoc analysis of the CRYSTAL study. ERJ Open Res. 2019;5(1):00243-2018. doi:10.1183/ 23120541.00243-2018 


\section{Publish your work in this journal}

The International Journal of COPD is an international, peer-reviewed journal of therapeutics and pharmacology focusing on concise rapid reporting of clinical studies and reviews in COPD. Special focus is given to the pathophysiological processes underlying the disease, inter-

protocols. This journal is indexed on PubMed Central, MedLine and CAS. The manuscript management system is completely online and includes a very quick and fair peer-review system, which is all easy to use. Visit http://www.dovepress.com/testimonials.php to vention programs, patient focused education, and self management read real quotes from published authors.

Submit your manuscript here: https://www.dovepress.com/international-journal-of-chronic-obstructive-pulmonary-disease-journal 